\title{
ПРАВОВЫЕ ПРОБЛЕМЫ РЕАЛИЗАЦИИ И ЗАЩИТЫ ПРАВ ИНТЕЛЛЕКТУАЛЬНОЙ СОБСТВЕННОСТИ НА ПРИМЕРЕ DIGITAL- ТЕХНОЛОГИЙ: ИСТОРИЧЕСКИЙ И ЮРИДИЧЕСКИЙ АСПЕКТЫ
}

\section{LEGAL PROBLEMS OF IMPLEMENTATION AND PROTECTION OF INTELLECTUAL PROPERTY RIGHTS ON THE EXAMPLE OF DIGITAL TECHNOLOGIES: HISTORICAL AND LEGAL ASPECTS}

\section{A. Tsaregorodtsev L. Dmitriev E. Shtekhman S. Zavyalov}

Summary: The article presents a comprehensive analysis of the legal mechanisms for the implementation of intellectual property rights in the digital sphere. The age of innovative technologies dictates new rules that should be followed by civil society in the conditions of digitalization of all spheres of life. The aim of the work is to study new aspects of the legal protection of intellectual property in the context of the formation and development of ideas about copyright and related rights within the framework of Continental European legal thought. When writing the article, historical-legal, formal-legal and technical-analytical methods were used.

The work reveals the possibilities of registering the code for writing websites as objects of intellectual property. As a result, examples of conflicts that may arise due to insufficient legal regulation of certain mechanisms for the protection of intellectual property in the field of digital technologies are given.

Keywords: copyright history, digital technologies, digital environment, intellectual property law, Internet, domain names, hashtags, websites.

\section{Царегородчев Алексей Васильевич}

К.и.н., дочент, Российская государственная академия интеллектуальной собственности, г. Москва

tsaregorodtsev1982@inbox.ru

Дмитриев Леонид Дмитриевич

Преподаватель, Российская государственная академия интеллектуальной собственности, г. Москва

sport-clasik@yandex.ru

Штехман Елена Александровна

Доцент, Российская государственная академия интеллектуальной собственности, г. Москва

shte-elena@yandex.ru

Завьялов Сергей Олегович

Аспирант, Российская государственная академия интеллектуальной собственности, г. Москва

S84716@yandex.ru

Аннотация: Статья представляет комплексный анализ правовых механизмов реализации прав интеллектуальной собственности в цифровой сфере. Век инновационных технологий диктует новые правила, которым стоит следовать гражданскому обществу в условиях цифровизации всех сфер жизни. Целью работы является изучение новых аспектов юридической защиты интеллектуальной собственности в контексте формирования и развития представлений об авторском праве и смежных правах в рамках континентально-европейской правовой мысли. При написании статьи использовались историко-правовой, формально-правовой и технико-аналитический методы. Работа раскрывает возможности регистрации кода написания сайтов в качестве объектов интеллектуальной собственности. В результате приводятся примеры коллизий, которые могут возникать в связи с недостаточным правовым регулированием отдельных механизмов защиты интеллектуальной собственности в области digital-технологий.

Ключевые слова: история авторского права, digital-технологии, цифровая среда, право интеллектуальной собственности, Интернет, доменные имена, хештеги, сайты.

Вопрос о генезисе понятия «интеллектуальная собственность» слабо изучен в исторической науке. В основном, эта проблематика находилась в поле чисто юридических наук, в частности, теории государства и права. В работах таких исследователей, как Л.А. Алехина, А.Г. Матвеев, М.В. Лабзин и др., затрагиваются отдельные аспекты зарождения представлений об авторском праве и интеллектуальной собственности, а также выявляются различные интерпретации этого понятия в историческом прошлом России и зарубежных стран. Однако цельная картина этого многопланового процесса пока не реконструирована.

Возникновение представлений об авторском праве 
тесно связано с формированием индивидуалистического сознания в эпоху Нового времени. В Средневековье, когда практически отсутствовал интерес к отдельно взятой личности, не могла возникнуть даже мысль об интеллектуальной собственности. Многие авторы не считали нужным подписывать свои произведения или подписывали именем более авторитетного мыслителя для придания большего веса изложенным мыслям. Так, неизвестный автор VII века подписывал свои богословские труды именем св. Дионисия Ареопагита, легендарного сподвижника апостола Павла. Не существовало в Средние века каких бы то ни было посредников на рынке интеллектуальных продуктов. Заказчик произведения живописи, скульптуры или литературы непосредственно контактировал с исполнителем и оплачивал его труд. Не возникало объективной необходимости в юридической защите интеллектуальной собственности.

Ситуация кардинально меняется с изобретением в середине пятнадцатого столетия печатного станка. Это была настоящая революция в духовной жизни Европы, имевшая множество значимых последствий, начиная от распространения грамотности и Реформации, и заканчивая появлением печатных СМИ. В то же время возникает новый субъект экономических отношений - издатель, ставший посредником между автором и потребителем интеллектуального продукта. Это создает объективную необходимость в юридической защите авторского права и борьбе с контрафактом [2]. Более отчетливым становится понимание того, что книга как материальный объект не тождественна тексту как духовному явлению.

Огромную роль в описываемом процессе играл сам факт бурного развития товарно-денежных отношений и формирование капиталистического уклада на заре Нового времени, в XV-XVI вв. Частная собственность постепенно выделяется из различных форм феодальной и общинной собственности и получает в ходе великих буржуазных революций XVII-XVIII столетий правовое закрепление. Формируется классическая триада правомочий собственника: владение, пользование, распоряжение.

По мере утверждения частной собственности как главнейшего правового института рыночных отношений вызревает представление о том, что она является неотъемлемым и фундаментальным правом каждого человека. Впервые наиболее отчетливо эта мысль звучит в трудах английского просветителя Джона Локка, сформулировавшего три естественных права: на жизнь, свободу и собственность [5]. Дальнейшее развитие концепция естественных прав получает в работах таких просветителей, как Шефтсбери, Болингброк, Вольтер, Д. Дидро, ж.-Ж. Руссо и др.

Все это было бы невозможно без такого важного социокультурного фактора, как рост индивидуалисти- ческих настроений Нового времени, обусловленный, как принято считать в исторической науке, развитием рыночных отношений, основанных на личной предприимчивости отдельно взятого индивида. Если результат крестьянского труда зависит от коллективных усилий и природной стихии, то купец или ремесленник обязан своим процветанием собственному трудолюбию и предпринимательскому таланту [3]. Индивидуализм как черта культуры эпохи Ренессанса проявляется в распространении портретной живописи, а также в желании авторов интеллектуальных произведений увековечить свое имя.

История правовой защиты интеллектуальной собственности начинается в «колыбели» капитализма - Великобритании. После Великой буржуазной (1640-1660) и Славной революции (1688-1689) были ликвидированы феодальные пережитки, мешавшие развитию рыночной экономики. Огромную роль сыграла и победа протестантизма в XVII веке, поскольку эта ветвь христианства нацеливала своих адептов на регулярное чтение Библии и другой духовной литературы, что не могло не способствовать бурному развитию книгопечатания. Достаточно вспомнить таких выдающихся религиозных мыслителей, как Дж. Баньян и Дж. Мильтон, которые активно публиковались в это время. Однако и светская литература также находит своих читателей, особенно с началом Просвещения. В 1710 г. королева Анна Стюарт подписывает парламентский акт, защищающий права авторов книг, карт и чертежей. Автор произведения получал на него исключительное право собственности на 14 лет с правом продления еще на такой же срок. Это первый правовой памятник защиты авторских прав в истории [18].

США с момента своего зарождения как колонии Великобритании развивались в уникальной социальноэкономической ситуации. Здесь, в отличие от Старого Света, не было практически никаких пережитков феодализма, и капиталистические отношения имели возможность почти беспрепятственного развития в XVII-XVIII вB. Так же будучи протестантской страной, с высокой степенью грамотности населения, США, победив Великобританию в войне за независимость, озаботились защитой авторских прав. В 1783 г. легислатура штата Коннектикут, а в 1790 г. Конгресс на федеральном уровне принимают законодательные акты, по смыслу аналогичные Статуту королевы Анны Стюарт.

Дальнейшее развитие законодательства об авторских и смежных правах в англосаксонских странах происходило по пути расширения объектов охраны за счет произведений искусства, изобретений и других продуктов творчества, а также увеличения срока их охраны. Так, в 1831 г. в США срок действия авторского права увеличивается до 42 лет.

История защиты авторских и смежных прав в рома- 
но-германской правовой семье начинается с Великой Французской революции и непосредственно вытекает из идеологии Просвещения, выдвинувшей на первый план фундаментальные права человека. На самом первом этапе революции, в 1791 г., Национальное собрание Франции принимает Декрет, закреплявший право автора на публичное представление своих произведений, а в 1793 г. уже Национальным Конвентом право на воспроизведение было включено в сферу правовой охраны. В девятнадцатом столетии в романо-германской правовой семье на основе ряда судебных прецедентов и законодательно было закреплен запрет на изменение произведения без согласия автора и копирование без указания его имени [17].

В России первый законодательный акт, защищающий авторские права появляется в XIX веке. Это закон 1830 г. «О правах сочинителей, переводчиков и издателей», который приравнял авторские права к правам собственности [19]. Дальнейшее развитие шло по пути расширения авторского права, включая под юридическую защиту сочинения композиторов, художников, скульпторов и т.д.

Проанализировав причины вызревания представлений и отправные точки в истории защиты интеллектуальной собственности, перейдем к проблеме ее концептуального осмысления в Новое и Новейшее время. Большое значение здесь имеет философия романтизма с ее концептом авторства и культом творческой личности. Произведение рассматривается как «отпечаток» мыслей, чувств, жизненного опыта автора, а значит, творец и продукт неотделимы друг от друга. Эта, казалось бы, очевидная мысль была новаторской для рубежа XVIII-XIX столетий. В это время тема связи автора и произведения выходит за рамки романтической философии и творчески переосмысливается И. Кантом в его работе «Критика способности суждения». Оригинальность интеллектуального труда, по мысли немецкого философа, является важнейшим признаком подлинного творчества, и только самостоятельное произведение заслуживает признания. Поскольку произведение рассматривается И. Кантом как продолжение личности автора, авторское право актуализируется им в контексте личных, а не вещных, прав. Любой интеллектуальный продукт понимается как публичное высказывание, автор которого имеет естественное право, чтобы никто не говорил от его имени без его согласия. Контрафактор понимается философом как лицо, которое ведет дела без поручительства (negotiorum gestor в римском праве). Таким образом, заслуга И. Канта состоит в том, что он интегрировал романтическую концепцию авторства с просветительской теорией естественных прав и римским правом [6]. Тем самым он прочертил траекторию эволюции представлений об авторском праве и смежных правах, характерную для континентально-правовой традиции и отличную от англосаксонской, где преобладала интерпретация этих прав в контексте прежде всего вещных правоотношений.

Более сложную концепцию авторского права сформулировал И.Г. Фихте. Он выделяет в авторском праве два аспекта: право на признание авторства (личное право) и право собственности на произведение (вещное право). При этом автор рассматривается как собственник не отдельных мыслей и идей, фигурирующих в произведении, а оригинального и неповторимого их сочетания.

Г.В.Ф. Гегель отрицал деление гражданских правоотношений на вещные и личные, полагая, что вещью может владеть только личность. Подобно И. Канту, но из совершенно других предпосылок, он рассматривал авторское право, как личное. Автор мыслился философом как собственник общего способа размножения его сочинений. Вопрос о том, является ли в философии Гегеля эта собственность отчуждаемой, представляется на данный момент дискуссионной в науке проблемой [7].

Если попытаться обобщить теоретико-правовую традицию осмысления авторского права и смежных прав в Новое и Новейшее время, то можно выделить несколько основных концепций. Персональная теория, восходящая к И. Канту и философам романтизма, рассматривает интеллектуальный продукт как продолжение личности автора, а авторское право, как личное. Договорная теория видит в исключительных правах автора на его произведение результат негласного договора с государством, которое заинтересовано в стимулировании общественно полезного интеллектуального труда. Эта концепция, очевидно, восходит к договорной теории государства, возникшей в рамках социальной философии Просвещения. Теория вознаграждения делает акцент на необходимости дать справедливое вознаграждение автору за его труд, обеспечить его материальное положение. Этой точки зрения придерживался отечественный правовед Г.Ф. Шершневич [8]. Утилитарная теория, получившая распространение в англосаксонской правовой традиции, восходит к философии утилитаризма И. Бентама. Защита авторского права рассматривается как способ стимулировать создание новых интеллектуальных продуктов. Проприетарная теория видит в продукте духовного творчества собственность автора, а в контрафакте кражу. Наконец, теория запрещения, созданная в начале XX века отечественным правоведом А.А. Пиленко и восходящая к взглядам немецкого юриста П. Лабанда, интерпретирует авторское право, как право творца запрещать другим субъектам использовать его произведение [4].

Подводя итоги ретроспективному анализу, отметим, что зарубежная и отечественная философская и теоретико-юридическая мысль имеет богатую традицию осмысления проблемы авторского права и смежных прав. В рамках этого научно-философского дискурса можно выделить существенное отличие англосаксонского и 
континентально-европейского подходов, выявление причин которого требует дальнейшего исследования, выходящего за рамки задач данной статьи.

В современном мире мы переживаем революцию в сфере интеллектуальной жизни, сопоставимую с изобретением книгопечатания в XV веке, что не может не повлиять на дальнейшее развитие института интеллектуальной собственности и механизмов ее правовой защиты. Речь идет о возникновении и развитии информационно-коммуникационных технологий.

Многогранность авторских, смежных с ними, патентных прав подтверждается активно меняющимся законодательством. А между тем, мы наблюдаем дефицит норм, регулирующих стремительно развивающуюся сферу digital-технологий, то есть сферу цифрового пространства, такую как Интернет, IT-маркетинг, социальные сети, веб-дизайн.

В Российской Федерации действует целый спектр законодательных актов, регулирующих защиту прав интеллектуальной собственности и устанавливающих пределы ответственности за правонарушения в этой области. Большое влияние на внутреннее законодательство оказывает целый ряд международных Конвенций, договоров и соглашений, в которых Россия принимает участие. У лица, которое справедливо считает, что его авторские или исключительные права нарушаются, в арсенале имеется ряд норм Уголовного, Гражданского Кодексов, а также КоАП, которые служат механизмом для защиты прав интеллектуальной собственности. Но мы остановимся на иных малоизученных моментах. В контексте инновационного и технического прогресса преобразуются и общественные отношения, и их правовое регулирование.

В условиях развития Интернет-торговли и digitalтехнологий стоит обратить внимание на рекламируемые бренды, логотипы, разрабатываемые для конкретных сайтов, и иные средства индивидуализации, к которым сейчас причисляют даже хештеги. Никакого юридического обоснования для запрета на регистрацию хештега в Роспатенте не выявлено. Но и эта новелла еще не закреплена в законодательстве. И суды в общей массе не воспринимают хештеги как самостоятельные объекты авторских прав. Между тем, для предпринимателей, ведущих электронную коммерцию через соцсети, именно хештеги служат маяком для идентификации их бренда и товара в многомиллионной аудитории. А будущее, как мы понимаем, в перспективе ведёт нас именно в сферу digital-технологий и электронную коммерцию. Поводов много: экономия на фактической аренде офиса, коммунальных платежах, транспортных расходах сотрудников. Пока на международном уровне регистрацией хештегов занимаются негосударственные компании. Портал
TWUBS предоставляет право при регистрации хештега формировать претензии, которые могут быть использованы в отношении любого товарного знака или другого юридического лица [1]. Но мы понимаем, что смысловой юридической нагрузки такое право, предоставленное иностранным порталом, в российской правовой системе не несет. Однако на примере последних событий с выборами и блокировкой аккаунта президента США, мы видим, что значимость соцсетей приобретает международную роль, откликающуюся и во внутригосударственной политике. Более того, мы видим, что решающие политические лозунги преобразовываются в хештеги, например \#No_Brexit [2, стр. 119]. Представители Роспатента подтверждают право использования хештега как средства индивидуализации товара [3].

За доменными именами также признается исключительное право согласно статье 1484 ГК РФ, если они содержат наименование товарного знака, что играет существенную роль для владельцев сайтов и предпринимателей. Некоторые исследователи настаивают на обособлении доменного имени от товарного знака, подчеркивая его индивидуальность [4, стр. 497]. При переходе права на доменное имя на нового владельца регистраторы требуют нотариального оформления такого действия, если у нынешнего администратора доменного имени нет возможности лично приехать в офис регистратора [5]. В связи с этим, следует различать права на контент и информацию, содержащуюся на самом сайте, и право на доменное имя. Так как этот вопрос еще мало изучен в Российской Федерации, то часто возникают коллизии. Иногда нотариусы отказывают в нотариальном удостоверении, так как не имеют представления, откуда берутся подобные требования. В случае нарушения прав в виде использования доменного имени на чужом ресурсе в любом виде, правообладатель в первую очередь на практике обращается к хостинг-провайдеру и к владельцу ресурса непосредственно с требованием удалить домен и выплатить компенсацию [6, стр. 53]. А в случае неудачи обращается в суд. Это позитивная практика, которая позволяет разгрузить суды.

В связи с этим возникает вопрос, как предпринимателям пользоваться всеми доступными возможностями, которые возникают в сфере использования цифровых ресурсов, и не нарушать чьи-то права? В качестве примера приведем ситуацию. Фирма выбирает оригинальное наименование товарного знака «mybrend» и регистрирует его в Роспатенте. При создании сайта, когда только идет процедура выбора доменного имени, регистратор доменных имен выводит не занятое доменное имя в зоне mybrend.ru, а в зоне mybrend.com оно уже используется неустановленным лицом. И российский пользователь, соответственно, регистрирует на себя имя в зоне mybrend.ru. Отсюда может возникнуть разночтение, нарушается ли право владельца аналогичного имени в 
зоне mybrend.com? Стоит предположить, что во избежание подобных коллизий уже на стадии разработки нового бренда или товарного знака, до его регистрации в Роспатенте, необходимо предварительно определять его уникальность в качестве доменного имени, если предполагается подобное его использование. Незаконное использование чужого доменного имени называется киберсквоттингом и преследуется во всем мире как преступление. В США принят специальный Закон о защите потребителей от киберсквоттинга. Стоит перенять эту практику и разработать российские аналоги норм и правил, регулирующих обращение, использование и защиту доменных имен.

Более того, помимо контента, состоящего из аудиои видеофайлов, текстов, слоганов и прочих атрибутов, владельцы сайтов патентуют использованные колористические решения в виде определённой html или rgba палитры в качестве промышленного образца. Далее, если исследовать непосредственно сайты, то помимо очевидных объектов (эксклюзивный литературный, мультимедийный или визуальный контент) стоит обратить внимание на сам код. Коды html, php, css, js регистрируют как программу для ЭВМ. С их помощью можно реализовать на сайте уникальную форму обратной связи или онлайн-калькулятор.
Среди негосударственных регуляторов, также отслеживающих сайты на предмет нарушения прав интеллектуальной собственности, выступают такие крупные международные и российский корпорации, как Google и Яндекс. B качестве примера приведем инструменты, используемые российской компанией Яндекс. При запуске рекламной кампании нового бренда или товарного знака, потребуется пройти модерацию, в процессе которой будет детальной изучен сайт, товарный знак или логотип, контент. И если возникают малейшие сомнения, служба Яндекс.Директ отклоняет по пункту 15 собственных правил, что для многих звучит как приговор [7]. По сложившейся практике еще ни разу не удалось опротестовать это. В последние годы Яндекс стал значительно злоупотреблять подобным правом, не давая никаких разъяснений по поводу отклонения, что вызывает справедливое возмущение среди пользователей сервиса Яндекс.Директ. Таким образом, мы видим, что постепенно в сферу защиты прав интеллектуальной собственности включаются структуры, которые не имеют установленных на государственном уровне полномочий, но играют решающую роль для предпринимателей. Этот пробел также должен стать поводом для законодательного урегулирования полномочий поставщиков услуг по продвижению рекламы в Интернете.

\section{ЛИТЕРАТУРА}

1. Алехина Л.А. Генезис категории «интеллектуальная собственность» и «исключительные права» в теории права XVIII - начало XX вв. (теоретико-правовой и историко-правовой аспекты). / Автореферат дис. ... кандидата юридических наук. - СПб, 2006.

2. Алехина Л.А. Эволюция авторского права. // История государства и права, 2006. №9. [Электронный ресурс]: https://demo.consultant.ru/cgi/online.cgi?req= doc\&base $=$ CJI\&n=14443\#09131245118922628 (дата обращения: 11.01 .2021 г.)

3. Антисери, Д., Реале, Дж. Западная философия от истоков до наших дней. От Возрождения до Канта. / Под ред. С.А. Мальцевой. - СПб., 2002.

4. Лабзин М.В. Научные концепции понимания права интеллектуальной собственности. [Электронный ресурс]: // https://www.intellectpro.ru/press/works/ nauchnye_kontseptsii_ponimaniya_prava_is/(дата обращения 12.01.2021 г.)

5. Локк, Дж. Два трактата о правлении. [Электронный ресурс]: // https://www.civisbook.ru/files/File/Lokk_Traktaty_2.pdf (дата 0бращения 12.01 .2021 г.)

6. Кант, И. Критика способности суждения. - М., 2020. [Электронный ресурс]: https://massolit.top/book/kritika-sposobnosti-suzhdeniya/reading (дата 06ращения: 09.01.2021 г.)

7. Матвеев А.Г. Личностное обоснование авторского права в контексте становления системы авторских прав в Германии. // Современные проблемы науки и образования, Пермь, 2015. №1-1. [Электронный ресурc]: https://science-education.ru/pdf/2015/1/1691.pdf (дата обращения 11.01.2021 г.)

8. Шершеневич Г.Ф. Курс торгового права. Т.Іl: Товар. Торговые сделки. - М., 2018. [Электронный ресурc]: https://static.my-shop.ru/product/pdf/248/24774417. pdf (дата обращения 10.01.2021 г.)

9. Twubs. Register hashtag // [Электронный ресурс] Режим доступа: URL https://twubs.com/p/register-hashtag (дата обращения: 20.01.2021).

10. Куликов С.Ю. Хештег как способ компрессии политических лозунгов (на материале твитов про брексит) // В сборнике: Проблемы и перспективы развития современной гуманитаристики: лингвистика, методика преподавания, культурология. Материалы Всероссийской научно-практической конференции. Редколлегия: Е.И. Абрамова (отв. ред.) [и др.]. 2020. С. 117-122.

11. Газета.Ru. «Роспатент исключил претензии к пользователям после регистрации хештега \#янебоюсьсказать». 26.08.2016 // [Электронный ресурс] Режим доступа: URL https://www.gazeta.ru/business/news/2016/08/26/n_9044063.shtml (дата обращения: 20.01.2021).

12. Хоменко Т.В. Право на доменное имя как разновидность интеллектуальных прав в цифровую эпоху // В сборнике: Трансформация права в информационном обществе. Материалы I Всероссийского научно-практического форума молодых ученых и студентов. Ответственный редактор 0. А. Пучков. 2019. C. 494-500.

13. Timeweb. Правила стандартной смены администратора // [Электронный ресурс] Режим доступа: https://timeweb.com/ru/help/pages/viewpage. action?pageld=11338012 (дата обращения: 20.01.2021). 
14. Грач 0.А. Нарушение прав на товарный знак при использовании доменного имени в сети «Интернет» // Бизнес, менеджмент и право. 2019. № 2. С. 50-54.

15. Яндекс. Правовые документы. Требования к рекламным материалам. Общие положения. // [Электронный ресурс] Peжим доступа: URL https://yandex.ru/ legal/general_adv_rules/ (дата обращения: 20.01.2021).

16. Абрамов С.А. Товарный знак в информационную эпоху // В сборнике: Информационное развитие России: состояние, тенденции и перспективы. Сборник статей Х всероссийской научно-практической конференции. Отв. редактор Ю.В. Каира. 2020. С. 334-339.

17. Матвеев А.Г. Некоторые сравнительно-правовые аспекты англо-американской и романогерманской концепций авторского права. // Вестник Пермского университета, 2009. Вып. 4 // [Электронный ресурс] http://www.jurvestnik.psu.ru/index.php/ru/vypusk-4-6-2009/10-2010-12-01-13-31-58/-4-6-2009/203nekot (дата обращения: 12.02 .2021$)$

18. Статут королевы Анны, 1710 г. // [Электронный ресурс:] https://web.archive.org/web/20160310020921/http://intellect-pravo.ru/documents/statute_of_ anne_rus.php (дата обращения: 12.02.2021)

19. 0 правах сочинителей, переводчиков и издателей. // Полное собрание законов Российской империи. Собрание второе, т. V. Отделение первое. 1830 год (№ 3399—3882), с. 17—21 // [Электронный ресурс:] https://dlib.rsl.ru/viewer/01003821763\#?page=18 (дата обращения: 12.02.2021)

○ Царегородцев Алексей Васильевич (tsaregorodtsev1982@inbox.ru), Дмитриев Леонид Дмитриевич (sport-clasik@yandex.ru),

Штехман Елена Александровна (shte-elena@yandex.ru), Завьялов Сергей Олегович (S84716@yandex.ru).

Журнал «Современная наука: актуальные проблемы теории и практики»

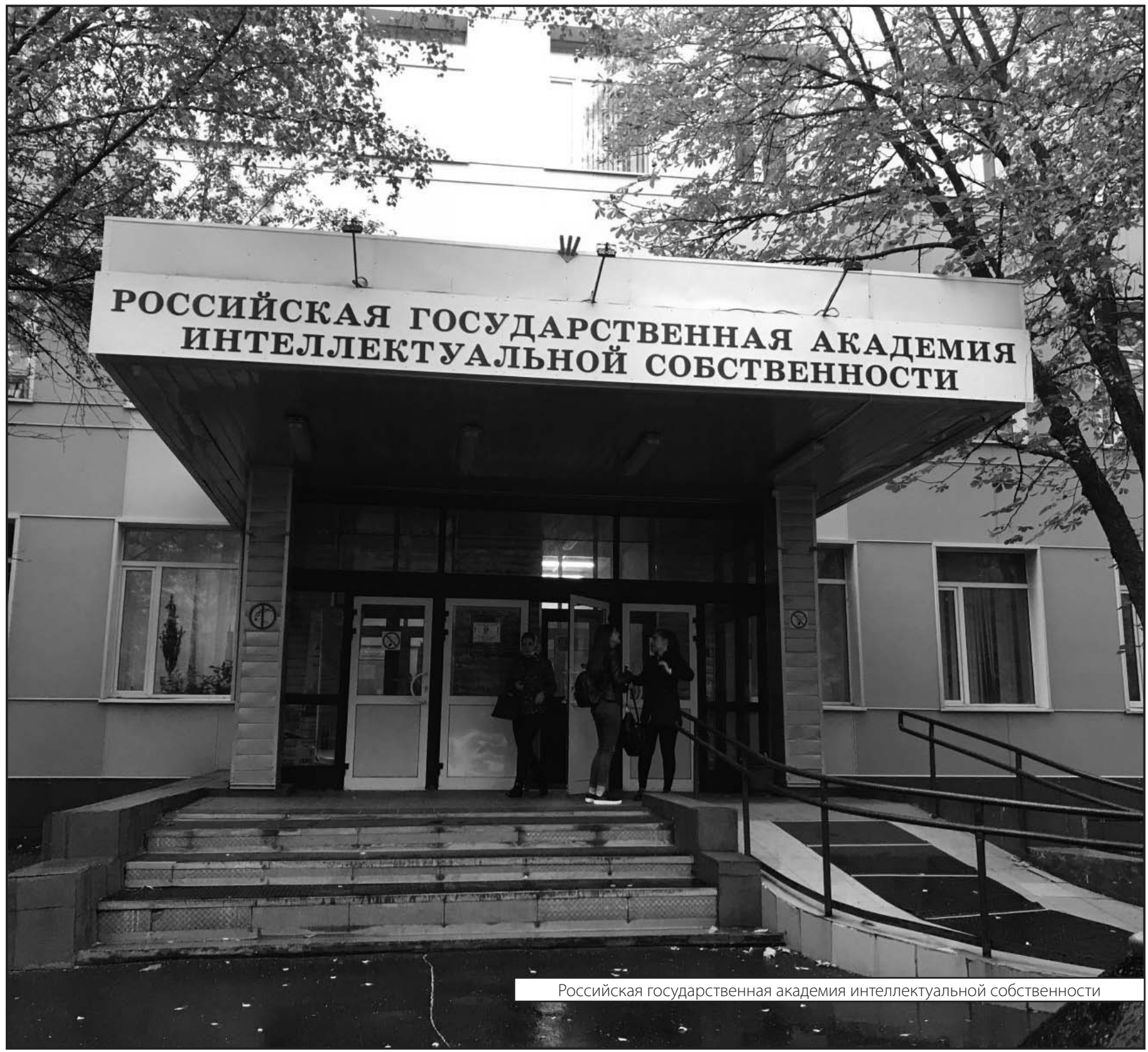

